LA W RENCE LIVERMORE N A TIO NAL LABORATORY
Isolation of Battery Chargers Integrated Into Printed Circuit Boards

J. S. Sullivan

November 26, 2013 
This document was prepared as an account of work sponsored by an agency of the United States government. Neither the United States government nor Lawrence Livermore National Security, LLC, nor any of their employees makes any warranty, expressed or implied, or assumes any legal liability or responsibility for the accuracy, completeness, or usefulness of any information, apparatus, product, or process disclosed, or represents that its use would not infringe privately owned rights. Reference herein to any specific commercial product, process, or service by trade name, trademark, manufacturer, or otherwise does not necessarily constitute or imply its endorsement, recommendation, or favoring by the United States government or Lawrence Livermore National Security, LLC. The views and opinions of authors expressed herein do not necessarily state or reflect those of the United States government or Lawrence Livermore National Security, LLC, and shall not be used for advertising or product endorsement purposes.

This work performed under the auspices of the U.S. Department of Energy by Lawrence Livermore National Laboratory under Contract DE-AC52-07NA27344. 


\section{Isolation of Battery Chargers Integrated Into Printed Circuit Boards}

Prepared by: Jim Sullivan, LLNL

\section{Problem:}

Present test procedures developed by the Federal Government (10 CFR Part 430 "Energy Conservation Program for Consumer Products”) to measure the energy consumption of battery chargers provide no method for the isolation of input power for battery chargers that have been integrated into printed circuit boards internal to electronic equipment. This prevents the measurement of Standby and Off Mode energy consumption. As a result, the energy consumption of battery chargers integrated into the printed circuit board cannot be measured.

\section{Battery Charging Systems:}

Battery charging systems are incorporated to a variety of electronic components - cell phones, tablet computers, notebook computers, hand-held instruments and digital cameras. The main component in the majority of battery charging systems for electronic components is the battery charging integrated circuit. Most battery charging ICs are based on Pulse Width Modulation (PWM), or Buck Converter technology. There is a wide variety of battery charging ICs available from a number of manufacturers. Battery charging IC capability ranges from simple linear battery charging to complete power management for the electronic component. The battery charging ICs vary in complexity from an eight-pin, single lithium-ion cell charger (Freescale MC 34673) to a 38-pin, dual battery charger that is controlled by a board mounted micro-controller via an SME bus (LTC 1960). There are also differences in the battery charging IC functions and requirements. Some ICs are fully integrated and require only input power to provide the battery charging function (LTC 1960). Other battery charging ICs require external circuitry (resistor dividers, MOSFETs, etc.) to provide charging voltage/current set-points and the ability to switch into and out of charging mode (MAX1909). Functions between battery charging ICs vary from a charging function alone (MAX 745, ST L6924D, Freescale MC34673) to the ability to charge a battery while also powering the system load for the electronic component (MAX 1909, LTC 1960, LTC 4090, Intersil ISL 6255, MAX 8934, TI bq24765). The latter battery charger ICs switch the external load to the battery source when external DC input power is removed. This is the type of system with which we are most familiar (notebook computers cell phones, etc).

\section{Issues:}

Most hand-held electronic components are designed to operate using battery power. These devices come equipped with battery chargers and applying the energy consumption measurements described in 10 CFR Part 430 is straight-forward. However, some devices are designed with the battery charging function integrated into the component internal circuitry. The example of a network router would fit into this category. In this case, the battery charger input power is derived from the DC power rail of the printed circuit board. Physical modification of 
the connections between the battery charging IC and the printed circuit board would have to be made to isolate the input power into the battery charger. These physical modifications would vary depending on the battery charging IC being used and its external components.

Figure 1 shows a schematic of a simple linear battery charging circuit based on a Maxim MAX745 lithium-ion battery charging IC. The DCIN pin of the MAX745 and the drain connection of N-channel MOSFET indicated would have to be de-soldered to provide isolation from the printed circuit board DC rail. A wire jumper from the printed circuit board DC connection to the DCIN pin and MOSFET drain would have to be installed to allow measurement of both input voltage and current into the battery charger. This modification would enable energy consumption measurements.

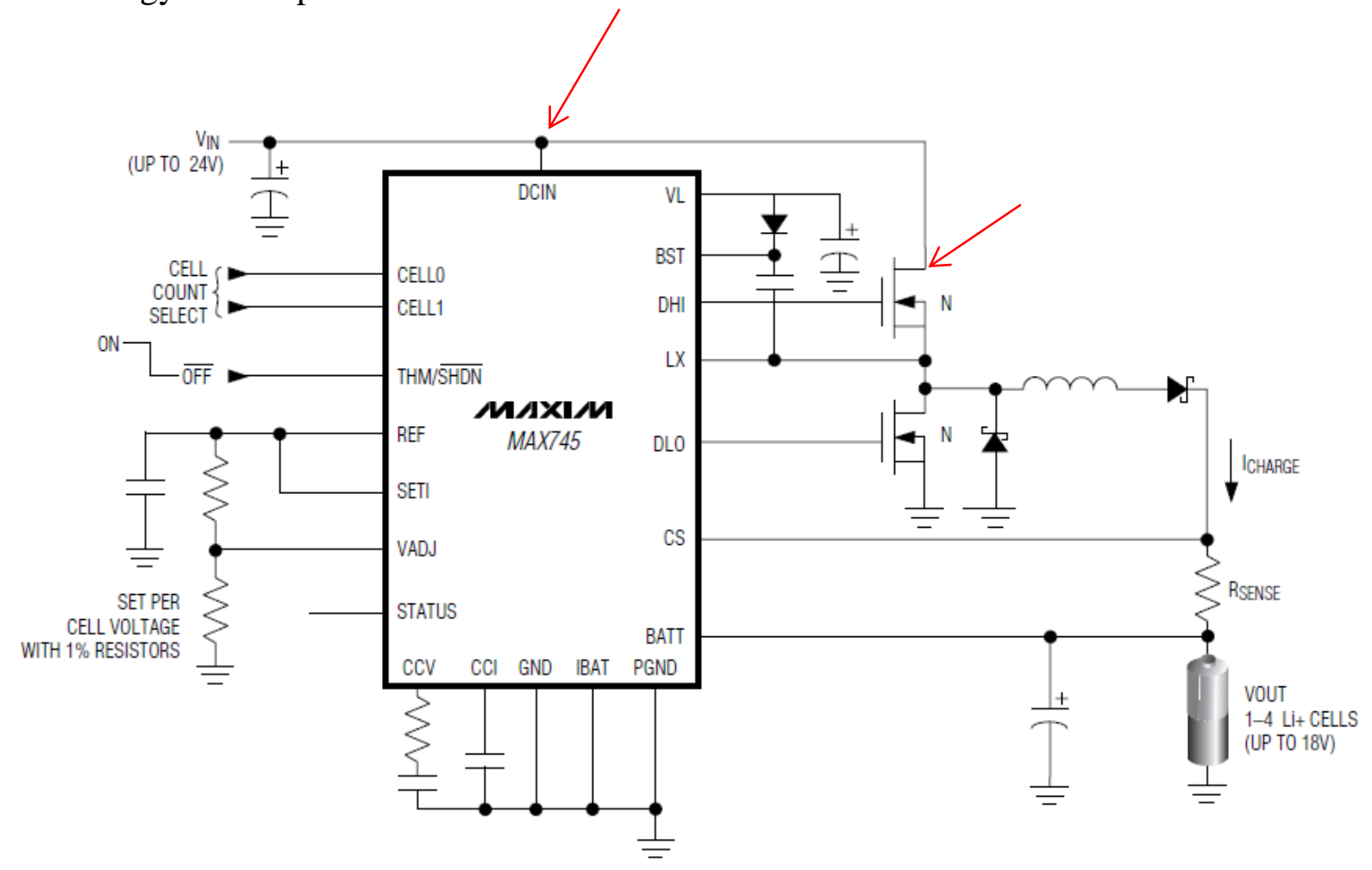

\section{Figure 1.}

Figure 2 shows a more complicated battery charging system based on a Linear Technology LTC 4090 battery charging IC. The LTC 4090 has provisions to charge a lithium-ion battery and power the system load via a DC input voltage derived from the printed circuit board, or a USB input. The lithium-ion battery will provide power to the system load upon loss of the DC input. The HVIN and HVEN pins on the LTC 4090 would have to be de-soldered from the printed circuit board to isolate the input power. A wire jumper would have to be installed between the printed circuit board DC rail and the HVIN and HVEN pins to enable input voltage and current measurement. An additional complication is the system load. The system load needs to be removed to perform the Standby and Off Mode energy consumption measurements of 10 CFR 
Part 430. The system load is usually removed by turning the electronic component off. If the electronic component does not have an off switch, other methods to remove the system load must be used.

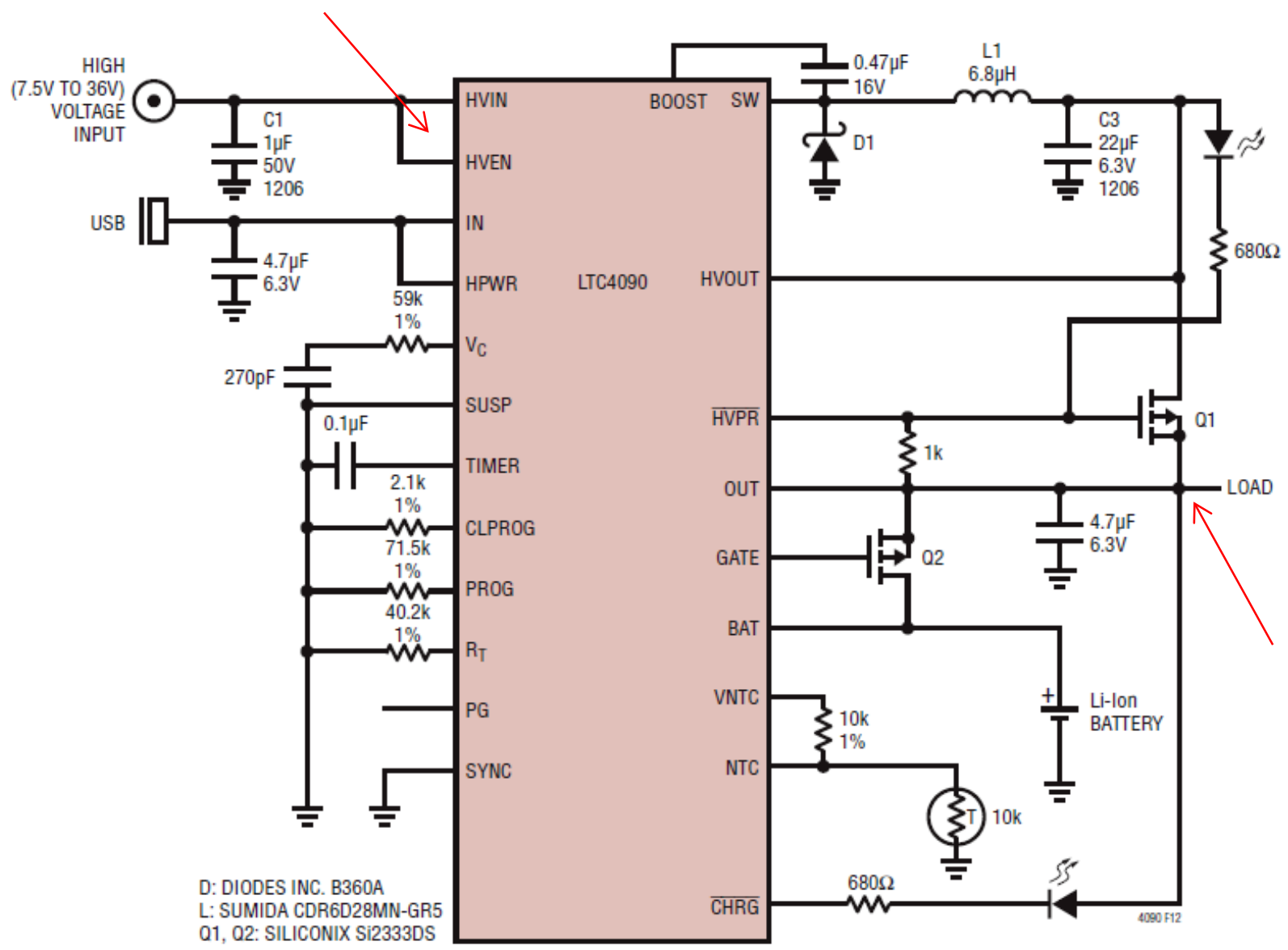

\section{Figure 2.}

\section{Conclusions:}

It is difficult to prescribe a general method to isolate the input power to battery charging ICs that have been integrated into the printed circuit boards of electronic components. The methods used to isolate the input power will depend on the specific battery charging IC being used and the functions that the charging IC provides. The methods used to isolate the input power to battery charger ICs that are integrated into electronic components will require an energy measurement technique that is closer to a trouble-shooting guide than a fixed, one size fits all, step by step procedure. An energy measurement procedure for battery charging ICs integrated into an electronic component will have requirements in addition to those identified in 10 CFR Part 430. Some of the additional requirements for measuring the energy efficiency of an integrated battery charging IC are: identification and understanding of the operation of the battery charging IC 
installed in the electronic component; capability to modify the printed circuit board/battery charging IC by de-soldering, or otherwise isolating IC/component pins; availability of any special equipment required to modify the printed circuit board/battery charging IC (for example, an anti-static pad and workbench); a worker that is qualified to perform the isolation of the battery charger and energy measurements. 